\title{
Two-colour pyrometry measurements of low-temperature combustion using borescopic imaging
}

\author{
Author, co-author (Do NOT enter this information. It will be pulled from participant tab in \\ MyTechZone) \\ Affiliation (Do NOT enter this information. It will be pulled from participant tab in MyTechZone)
}

\begin{abstract}
Low temperature combustion (LTC) of diesel fuel offers a path to low engine emissions of nitrogen oxides (NOx) and particulate matter (PM), especially at low loads. Borescopic optical imaging offers insight into key aspects of the combustion process without significantly disrupting the engine geometry. To assess LTC combustion, two-colour pyrometry can be used to quantify local temperatures and soot concentrations (KL factor). High sensitivity photo-multiplier tubes (PMTs) can resolve natural luminosity down to low temperatures with adequate signal-to-noise ratios. In this work the authors present the calibration and implementation of a borescope-based system for evaluating low luminosity LTC using spatially resolved visible flame imaging and high-sensitivity PMT data to quantify the luminous-area average temperature and soot concentration for temperatures from $1350-2600 \mathrm{~K}$. The visible flame area is used to adjust the PMT measurements to account for sooting area (i.e., the fraction of the region of interest that contains discernible flame/natural luminosity). The validity of the approach is assessed using spatially resolved temperature and soot concentration data collected from a full optical single-cylinder engine operating using non-premixed natural gas combustion, with soot concentrations similar to those seen in the LTC data. The high sensitivity and low noise of the PMTs, combined with the broad field of view of the borescope, and the proposed sooting area correction method, provide robust measurement of flame temperature and KL factor in low temperature and low-sooting combustion conditions. Whilst the sooting area correction is found to have only a small effect on the measured temperature, it is shown to be important to provide soot concentrations that are representative of spatially resolved results. This work provides new insights into the use of relatively low-cost, high sensitivity PMTs to assess advanced and low-emission combustion systems.
\end{abstract}

\section{Introduction}

Diesel engines achieve high efficiency and high power density, making them well suited to many current vehicular applications. To minimize their impact on ambient air quality, current diesel engines use complex and expensive exhaust aftertreatment systems to meet regulatory requirements on nitrogen oxides $(\mathrm{NOx})$ and particulate matter (PM) emissions. Engine technologies need to continue to be developed to meet ever more stringent standards while also improving efficiency and cold-start performance. An approach that offers potential to control emissions, especially during cold-start and part-load operation, is low-temperature combustion (LTC). While this combustion approach can offer near-zero NOx and PM emissions, combustion instability and poor fuel-conversion efficiency Page 1 of 16 can occur if the full system is not controlled carefully. To improve LTC, it is critical to understand better the in-cylinder combustion processes. Optical access can provide valuable insight, but low combustion luminosity in LTC is a challenge, while the engine modifications needed for full-cylinder optical viewing can impact the combustion performance. This work focuses on the use of highsensitivity optical combustion assessment using a cylinder-head mounted borescope in a high-speed diesel engine equipped with an unmodified piston operating under LTC regimes.

To control NOx emissions, it is vital to reduce local charge temperatures; but this can often lead to high PM emissions in diesel engines. To simultaneously reduce NOx and PM, various lowtemperature strategies have been combined with high degrees of premixing, reducing the opportunities for rich, high-temperature zones that favour the formation of black carbon soot precursors [1]. One effective in-cylinder technique to reduce $\mathrm{NOx}$ in a diesel engine is exhaust gas recirculation (EGR), which reduces the local oxygen concentration, leading to lower local combustion temperatures and reduced $\mathrm{NO}_{\mathrm{X}}$ formation [2]. EGR levels $>\sim 50 \%$ can result in NOx emissions below $15 \mathrm{ppm}$, but soot emissions remain significant. Very high levels of EGR ( $>\sim 60 \%$ by volume) retain ultra-low NOx levels, while the long ignition delay due to this high dilution leads to significant fuel premixing, substantially reducing in-cylinder soot formation $[3,4]$. However, the low temperatures and reduced incylinder oxygen concentrations of high-EGR LTC can lead to high combustion by-product emissions (e.g. CO, hydrocarbons) and correspondingly lower combustion efficiency $[3,5,6]$.

A key challenge of high-EGR LTC is to achieve near-zero NOx with low soot, without compromising thermal efficiency or increasing combustion by-product emissions. Connecting tailpipe emissions to in-cylinder processes offers understanding that can be used to optimize the combustion system under varying operating conditions. However, low flame temperatures combined with low in-cylinder soot concentrations result in low emissions of broadband thermal radiation, making optical assessment challenging. This is critical for operation in high-EGR LTC and for managing transitions between LTC and conventional diesel combustion modes.

Optical measurement techniques can help to determine in-cylinder conditions and processes. Two-colour pyrometry provides quantitative soot temperature along the line-of-sight of a flame. It also provides a semi-quantitative soot concentration by quantifying the optical thickness along the line-of-sight; this thickness can be related to soot concentrations depending on the optical properties of the radiating medium (soot). It works by measuring radiant emission intensity at two carefully selected wavelengths, then relating these 
two intensities to the expected emissions of a grey body. From the ratio of intensities, both the temperature of the grey body and its soot concentration can be found. Two-colour pyrometry is well suited for combustion studies in conventional diesel combustion systems as radiation emission are typically dominated by soot incandescence. The temperature difference between the soot particles and the surrounding gases has been shown to be negligible $(<1 \mathrm{~K})$ for diesel flame conditions [7]. Two-colour pyrometry (both spatial-averaged and spatial-resolved) has been implemented to measure maximum flame temperature in a diesel engine up to $2800 \mathrm{~K}$ and is typically optimized for temperature ranges of 1900-2800 K $[8,9,10]$. The methodology will be challenged under conditions where temperatures and soot concentrations are low, such as in low temperature combustion.

The measurement of flame temperature in low temperature diesel combustion engines is not widely reported with only a few studies known to the authors $[11,12,13,14]$ with reported temperatures using two-colour pyrometry down to $1650 \mathrm{~K}$. Most of the optical studies have been conducted on purpose built optical engines, where a Bowditch extended piston is combined with an optical window in the piston bowl to provide spatially resolved images. Such a nonrepresentative piston bowl will significantly impact the interaction between the diesel spray and the piston. This is a particularly important consideration under high-dilution low-temperature combustion, where partial premixing is a critical aspect of the combustion process. In many studies conducted on fully optically accessible engines, charge dilution is achieved using $\mathrm{N}_{2}$ and/or $\mathrm{CO}_{2}$ instead of recirculated exhaust gases. The presence of water vapour influences end-of-compression temperature due to its influence on the specific heat of the charge, and on the ignition process due to availability of reactive species. When EGR is simulated with a mixture of $\mathrm{N}_{2}$ and $\mathrm{CO}_{2}$, the lack of water vapour results in longer ignition delay, $\mathrm{CO}$ and hydrocarbon emissions, and lower soot emissions in high-dilution LTC [15].

Two colour pyrometry can be either spatially resolved or field-ofview integrated. Using high-speed photography, spatially resolved temperatures and soot concentrations can be estimated. While care needs to be taken in both data collection and interpretation [16], valuable understanding can be gained. The sensitivity of the camera will limit the measurable range of temperatures and soot concentrations before the signal to noise ratio (SNR) becomes too low. Under conditions with low radiant intensities, such as low temperature diesel combustion, low-noise, high quantum efficiency photo-multiplier tubes (PMTs) can be used to measure field-of-view integrated radiant emissions. These can be used in either a fully optically accessible engine or in a less-modified engine by using a borescopic probe inserted through the cylinder head.

Spatially integrated two-colour pyrometry trades information (spatial temperature distribution) for sensitivity. By averaging the radiant intensity over the full field of view, measured temperature and soot concentrations become sensitive to variations in radiant intensity across the field of view of the sensor. Zhao and Ladommatos [17] reported that when only part of the field of view is filled with combustion gas, the brightness temperature of the flame will be underestimated; they recommended keeping the field of view of an area-integrated system narrow to reduce the possibility of having significant portions of the field of view unfilled. This small area increases the likelihood of findings that are not representative of the general state within the combustion chamber and also reduces the sensitivity of the instrument due to less radiation reaching the sensor. This is particularly important for low temperature combustion regimes when the luminous radiation is low and does not consistently fill the field of view of the optical probe [4].
Accounting for the changing radiating area as a function of crank angle is paramount to obtain accurate two-colour pyrometry data. For optically accessible engines, PMTs and high-speed cameras have been used to measure flame radiation and luminous/sooting area simultaneously in engines $[12,16,18]$. In these cases, the soot areadefined as the fraction of the full field of view where the camera could detect radiant emissions in the visible wavelengths - was used to calculate the monochromatic radiation intensity at each wavelength.

The objective of the present work, therefore, is to develop a PMTbased two-colour pyrometry system to measure flame temperature in low-temperature and low soot combustion regimes and to adapt the methodology of Musculus et al. $[12,18]$ to demonstrate the effect of the proposed sooting area correction method on flame temperature and KL factor. It should also be noted that PMTs with variable gain settings were used as sensors in this work. The variable gain settings of the PMTs ensure that low gain settings could be used while measuring temperature in the high temperature conventional diesel combustion, while high gain settings could be used for temperature measurement in the low temperature combustion regimes without affecting the signal to noise ratio of the system. Combining high sensitivity PMTs with spatial flame luminosity images recorded through the same borescope configuration offers in-depth interpretation of low-temperature combustion under conditions that closely resemble those in a standard engine. It should be noted that this work also allows to understand the limitations of spatially integrated vs. imaged pyrometry. The former is much easier to implement, but there is not much discussion in the literature of how such integrated measurements should be interpreted.

\section{Description of Two-colour Pyrometry}

The theory and implementation aspects of the two-colour method have been reported by several authors $[17,19,20]$ and are only discussed here briefly. From Planck's radiation law, the monochromatic black body radiance (a function of temperature, $\mathrm{T}$ and wavelength, $\lambda$ ) may be expressed as

$$
I_{b}(\lambda, T)=\frac{c_{1} \lambda^{-5}}{\left(e^{c_{2} / \lambda T}-1\right)}
$$

where $c_{1}$ and $c_{2}$ are constants; $c_{1}=2 \pi h c^{2}$ and $c_{2}=h c / k_{\mathrm{b}}, h$ is the Planck constant, $k_{b}$ the Boltzmann constant and $c$ the speed of light.

The monochromatic emissivity $\left(\varepsilon_{\lambda}\right)$ is estimated for soot particles using the empirical correlation of Hottel and Broughton [21], and expressed as

$$
\varepsilon_{\lambda}\left(\lambda, f_{v}, L\right)=1-e^{\left(-k_{\text {soot }} L / \lambda^{\alpha}\right)}
$$

where $\mathrm{k}_{\text {soot }}$ is the soot absorption coefficient, a variable proportional to the soot volume fraction $\left(f_{v}\right)$ and $\alpha$ is a constant, which depends on the physical and optical properties of soot in the flame. The optical path length (L) is the longest distance from which radiation reaches the optical sensor and is proportional to the flame thickness. Due to the exponential relationship between emissivity and optical path length, a linear relationship is not always possible between the optical and geometrical length and hence, the emissivity within the optical path is usually expressed in terms of the product $\mathrm{KL}=\mathrm{k}_{\text {soot }} \mathrm{L}$ [19].

The explicit dependence of radiance on temperature, soot concentration (absorption coefficient, volume fraction and physical properties) and wavelength can be expressed as 


$$
I_{\text {soot }}(\lambda, \mathrm{T}, \mathrm{KL})=\left[1-e^{\left(-k_{\text {soot }} L / \lambda^{\alpha}\right)}\right]\left[\frac{c_{1} \lambda^{-5}}{\left(e^{c_{2} / \lambda T}-1\right)}\right]
$$

There are two unknowns in Equation (3): T and KL. However, both of these are theoretically insensitive to the wavelength being measured. As a result, by measuring radiant intensity at two distinct wavelengths, the above equation can be solved for either T or KL. For the flame temperature, T, KL can be eliminated by rewriting Equation (3) for two specific wavelengths, $\lambda_{1}$ and $\lambda_{2}$ to leave,

$$
\left[1-\left(\frac{e^{\left(c_{2} / \lambda_{1} T\right)}-1}{e^{\left(c_{2} / \lambda_{1} T_{a 1}\right)}-1}\right)\right]^{\lambda_{1}^{\alpha 1}}=\left[1-\left(\frac{e^{\left(c_{2} / \lambda_{2} T\right)}-1}{e^{\left(c_{2} / \lambda_{2} T_{a 2}\right)}-1}\right)\right]^{\lambda_{2}^{\alpha 2}}
$$

Equation (4) can then be solved for, T, when the two apparent temperatures, $T_{a 1}$ and $T_{a 2}$ are known for the two wavelengths $\lambda_{1}$ and $\lambda_{2}$. These two apparent temperatures are determined by calibrating the two-colour pyrometer at the selected wavelengths using a black body light source at a known temperature. It should be noted that these relations do not consider spatial variations, and thus a spatially integrated apparent temperature measurement assumes a homogeneous radiant intensity.

Equation (3) provides the soot spectral radiance, which is the emitted power per solid angle per unit wavelength per unit emitted area normal to the emitted rays. While deriving Equation (4) from the algebraic manipulation of Equation (3) at two different wavelengths, the implicit assumption is that the emitting area does not change and thus constant even as cylinder volume changes due to piston motion, or the soot cloud shape changes due to soot formation, oxidation, or advection. If the emitting area is not constant, as may be the case in area-integrated pyrometry, then using Equation (4), without correcting for sooting area may provide inaccurate two-colour results. Therefore, it is important to correct the monochromatic radiation intensities (and hence, the apparent temperatures at two wavelengths) with sooting area.

The 'uncorrected' soot emissive power, $S_{\lambda, \text { uncorrected }}$, from an optical detector viewing a radiating soot cloud may be expressed as

$$
S_{\lambda, \text { uncorrected }}=C_{\lambda} \cdot I_{\text {soot }}(\lambda, \mathrm{T}, \mathrm{KL})
$$

which is obtained from the simplification of the following triple integral equation with certain hypotheses [18]

$$
S_{\lambda}=\iiint_{\lambda \Omega A} H_{D e t}(\lambda) \cdot I_{\text {soot }}(\lambda, \mathrm{T}, \mathrm{KL}) \cdot d \lambda \cdot d \Omega \cdot d A
$$

where $H_{\text {Det }}(\lambda)$ is the detector transfer function, $A$ is the area within the field of view (FOV) of the detector and $\Omega$ is the solid angle subtended by the detector area. $C_{\lambda}$ is the calibration constant, which accounts for the three integral variables (i.e., area, solid angle and wavelength) in Equation (6). $C_{\lambda}$ is obtained from the calibration of the system.

From Equation (5), the uncorrected soot emission flux $\left(S_{\lambda}\right.$ per unit area within the field of view of the detector, $A_{F O V}$ ) can be calculated as

$$
\frac{S_{\lambda, \text { uncorrected }}}{A_{F O V}}=\frac{C_{\lambda \cdot I_{\text {soot }}(\lambda, \mathrm{T}, \mathrm{KL})}}{A_{F O V}}
$$

Therefore, the 'sooting area corrected' signal $\left(S_{\lambda, \text { corrected }}\right)$ will be

$$
\begin{gathered}
S_{\lambda, \text { corrected }}=\frac{C_{\lambda \cdot I_{\text {soot }}(\lambda, \mathrm{T}, \mathrm{KL})}}{A_{F O V}} \cdot A_{\text {soot }} \\
\rightarrow S_{\lambda, \text { corrected }}=S_{\lambda, \text { uncorrected }} \times \frac{A_{\text {soot }}}{A_{\text {FoV }}}
\end{gathered}
$$

where $\frac{A_{\text {soot }}}{A_{\text {FOV }}}$ is the sooting area fraction.

The 'uncorrected' and 'sooting area corrected' apparent temperatures are deduced from soot emissive power expressions $\left(S_{\lambda, \text { uncorrected }}\right.$ and $S_{\lambda, \text { corrected }}$ ) from Equations (5) and (9), respectively.

\section{Experimental Apparatus}

The work was conducted on a fully instrumented AVL singlecylinder diesel engine, representative of an automotive two-litre fourcylinder light-duty engine. The base engine piston geometry was retained and a borescope was inserted through the cylinder to provide optical access, connected to either PMTs, for area integrated results, or a camera to provide in-cylinder flame imaging. Diesel (automotive grade ultra-low sulphur, meeting BS EN590) was injected with a five-hole centrally mounted injector fed from a Bosch CP3 common rail system. The engine was equipped with a custom boost and EGR system, including intake and exhaust pressure control to independently control charge mass and dilution rates; more details on the system configuration are provided elsewhere [22]. Details of the specification of the engine, fuelling system and fuel used are given in Table 1.

Table 1: Single cylinder research engine and fuelling system specifications
\begin{tabular}{|l|l|}
\hline Research Engine & $\begin{array}{l}\text { AVL } 5402 \text { Single cylinder } \\
\text { diesel }\end{array}$ \\
\hline Engine type & $85 / 90 / 148 \mathrm{~mm}$ \\
\hline Bore/Stroke/Connecting rod length & 0.511 \\
\hline Swept volume & $17.1: 1$ \\
\hline Compression ratio & $4200 \mathrm{rpm}$ \\
\hline Rated speed & 1.78 \\
\hline Swirl ratio & \\
\hline Fuelling System & Bosch common rail \\
\hline Injection system & $135 \mathrm{MPa}^{-1}$ \\
\hline Maximum rail pressure & VCO \\
\hline Nozzle type & $5 / 0.18 \mathrm{~mm}^{-1}$ \\
\hline Number of holes/Diameter & $142^{\circ}$ \\
\hline Spray included angle & \\
\hline Fuel * & $840 \mathrm{~kg} \cdot \mathrm{m}^{-3}$ \\
\hline Density at $15^{\circ} \mathrm{C}$ & $9 \%{ }_{\text {mass }}$ \\
\hline Polycyclic aromatic hydrocarbon (PAH) & 52 \\
\hline Cetane number & $8 \mathrm{mg} \cdot \mathrm{kg}^{-1}$ \\
\hline Sulphur content &
\end{tabular}

* Values provided by the supplier

The research facility was instrumented to measure air temperature and pressure, fuel and air flow rates and in-cylinder pressure. The crank-angle was measured with a resolution of $0.5^{\circ} \mathrm{CA}$ by an AVL 365 optical crank angle encoder mounted directly on the engine crank shaft. In-cylinder pressure was measured using a flush-mounted water-cooled AVL QC34C quartz piezo-electric pressure transducer. The in-cylinder pressure was used to calculate the apparent net energy release rate, defined as the difference between the energy released due to combustion of fuel and energy loss due to heat transfer and crevice flows. The standard $1^{\text {st }}$ Law definition of net 
energy release rate is used [23] assuming a constant specific heat ratio of 1.33. Emissions measurements to determine the concentrations of $\mathrm{CO}_{2}$ and $\mathrm{NOx}$ in the exhaust were made using a Horiba Mexa 7100HEGR emission analyser. This system also measured the intake $\mathrm{CO}_{2}$ concentration to determine the EGR level. An AVL 415 smoke meter was used to determine exhaust smoke emissions in terms of filter smoke number (FSN).

\section{Optical Configuration}

The research engine was equipped with a custom cylinder head that allowed for borescopic access. To accomplish this, one of the engine's two exhaust valves was removed and an installation tube was inserted through the cylinder head, with a fused silica optical window attached at the end which protruded slightly into the combustion chamber. The removal of one exhaust valve tends to increase residual fraction by a small amount (from $3.3 \%$ to $4.3 \%$ ) [22]. While this will impact the total in-cylinder oxygen content, the impacts on the combustion process at $1500 \mathrm{rpm}$ and 3 bar indicated mean effective pressure (IMEP) operating condition was shown to be negligible [24] compared to the more invasive optical techniques [15]. The borescope used in this work had a $67^{\circ} \mathrm{FOV}$ to image a wide area within the combustion chamber; further details are provided in Table 2. Figure 1 details the borescope's FOV within the combustion chamber. For flame imaging, the borescope was connected to a monochrome charge coupled device (CCD) camera (Pro-Silica GC1380) with a Pentax Machine Vision Mega-Pixels lens triggered based on crank-angle position; more details on the optical configuration are provided elsewhere [22]. Due to the limited speed of the camera, crank angle resolved images were captured from sequential cycles. A minimum of 10 images were recorded at each pre-defined crank angle and then ensemble-averaged using Image Pro Plus software to provide a representative measure of the visible broadband radiation emissions at each crank angle.

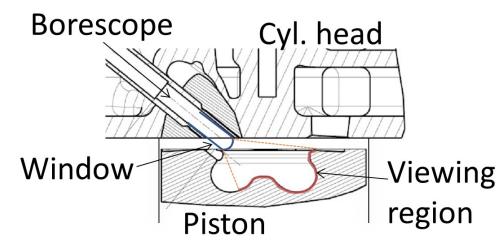

a) cross-section through

Borescope centreline

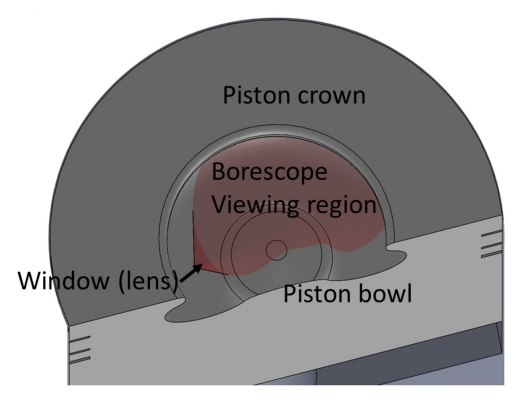

b) viewing region in piston bowl

Figure 1: Borescopic installation and field of view. (a) cross section showing borescope installation and viewing area (Adapted from [25]); (b) field of view of borescope at $10{ }^{\circ} \mathrm{CA}$ ATDC, shaded area shows surface of piston that can be seen through borescope
Table 2 Two-colour pyrometry system components

\begin{tabular}{|c|c|c|}
\hline Components & Make/Model & Specifications \\
\hline $\begin{array}{l}\text { Optical } \\
\text { window }\end{array}$ & AVL/BO2737 & Fused silica \\
\hline Borescope & Karl-Storz/84583A & $\begin{array}{l}\text { Anti-reflective coated } \\
\text { borosilicate (BK } 7 \text { ) glass; } \\
\text { Field of view: } 67^{\circ}\end{array}$ \\
\hline $\begin{array}{l}\text { Dichroic } \\
\text { mirror }\end{array}$ & Hamamatsu/DM660 & $\begin{array}{l}\text { Reflectance }>95 \% \text { between } \\
460-625 \mathrm{~nm} ; \\
\text { Transmittance }>90 \% \text { above } \\
625 \mathrm{~nm}\end{array}$ \\
\hline $\begin{array}{l}\text { Interference } \\
\text { filters }\end{array}$ & $\begin{array}{l}\text { Thorlabs / FB05550- } \\
\text { 10-SP FB05700-10-SP }\end{array}$ & $\begin{array}{l}\text { Centre wavelength: } 550 / 700 \\
\mathrm{~nm} ; \\
\text { Full width at half maximum: } \\
10 \mathrm{~nm} \text {; } \\
\text { Minimum transmissivity: } \\
>50 \%\end{array}$ \\
\hline $\begin{array}{l}\text { Amplified } \\
\text { photomultiplier } \\
\text { tube module }\end{array}$ & Hamamatsu / H5784-20 & $\begin{array}{l}\text { Spectral response: } 300-900 \mathrm{~nm} \text {; } \\
\text { Peak sensitivity wavelength: } \\
630 \mathrm{~nm} \text {; }\end{array}$ \\
\hline Camera & Prosilica / GC 1380 & $\begin{array}{l}\text { Imaging device: } 2 / 3 \text { " Sony } \\
\text { ICX285AL; } 1360 \times 1024 \text { pixels } \\
\text { (cell size: } 6.45 \times 6.45 \mu \mathrm{m} \text { ); } \\
\text { Max. Quantum efficiency: } \\
70 \% \text {; Camera speed at } \\
\text { maximum resolution: } 20 \\
\text { frames/s (fps) }\end{array}$ \\
\hline
\end{tabular}

An important consideration for two-colour pyrometry is the selection of which two wavelengths to use. In the temperature ranges of 1500$2000 \mathrm{~K}$, which are of particular interest in LTC, Plank's distribution suggests that soot emissive power falls to a very low level below $\sim 500 \mathrm{~nm}$; radiative emissions are concentrated in the infrared (IR) part of the spectrum $(\lambda>740 \mathrm{~nm})$. However, the antireflective coating in the borescope used in this work resulted in a significant reduction in transmissivity in the near-IR spectrum, restricting the work to visible wavelengths. Visible-light wavelengths have the added benefit that the sensitivity of the flame temperature and KL factor calculations to the value of $\alpha$ in Equation (4) is reduced and a fixed value (1.39) can be used [17, 21], which is not generally the case with IR $[17,26]$. Finally, careful selection of wavelengths in the visible spectrum can avoid chemiluminescence from reactive species (e.g., $\mathrm{CH}, \mathrm{C}_{2}, \mathrm{NH}_{2}, \mathrm{CH}_{2} \mathrm{O}$ ) [27] while avoiding absorption by combustion products such as $\mathrm{CO}_{2}$ and $\mathrm{H}_{2} \mathrm{O}$ [28]. Based on these considerations, combined with the desirability of increasing sensitivity by maintaining a significant difference in wavelengths, the pyrometry system was designed for $550 \mathrm{~nm}$ and $700 \mathrm{~nm}$ [22].

\section{Pyrometry Setup and Calibration}

The two-colour pyrometer system is composed of a pair of photomultiplier tubes (PMTs) connected to the borescope with a dichoric mirror and fitted with interference filters, as shown in Figure 2 and described in more detail in Table 2 . This system was calibrated with a pre-calibrated tungsten strip lamp ( $3 \mathrm{~mm}$ width) to determine the apparent temperatures, $T a_{1}$ and $T a_{2}$ at $\lambda_{1}$ and $\lambda_{2}$ so that the voltage output from the PMT (radiation intensity) could be correlated with the apparent temperature. These lamps have been shown to be suitable calibration sources [7,29]. The tungsten strip lamp used in this work was calibrated by the manufacturer against a standard blackbody at a wavelength of $660 \mathrm{~nm}$; more details about the tungsten lamp are available elsewhere [30]. For calibration of the pyrometer system, the apparent temperature of the tungsten lamp was 
calculated at the two pyrometer wavelengths - 550 and $700 \mathrm{~nm}$ - for a range of temperatures. First, the true lamp temperature was determined from the apparent temperature at $660 \mathrm{~nm}$ and emissivity of tungsten by means of Wien's law of radiation:

$$
\frac{1}{T}=\frac{1}{T_{a}}+\frac{\lambda}{C_{2}} \log _{e} \varepsilon_{\lambda}
$$

where the spectral emissivity $(450-800 \mathrm{~nm})$ of tungsten as a function of true temperature (between 1300-2000 K) was calculated using the empirical correlations proposed by Larrabee [31] and the calculation method outlined by Lu and Yan [32].

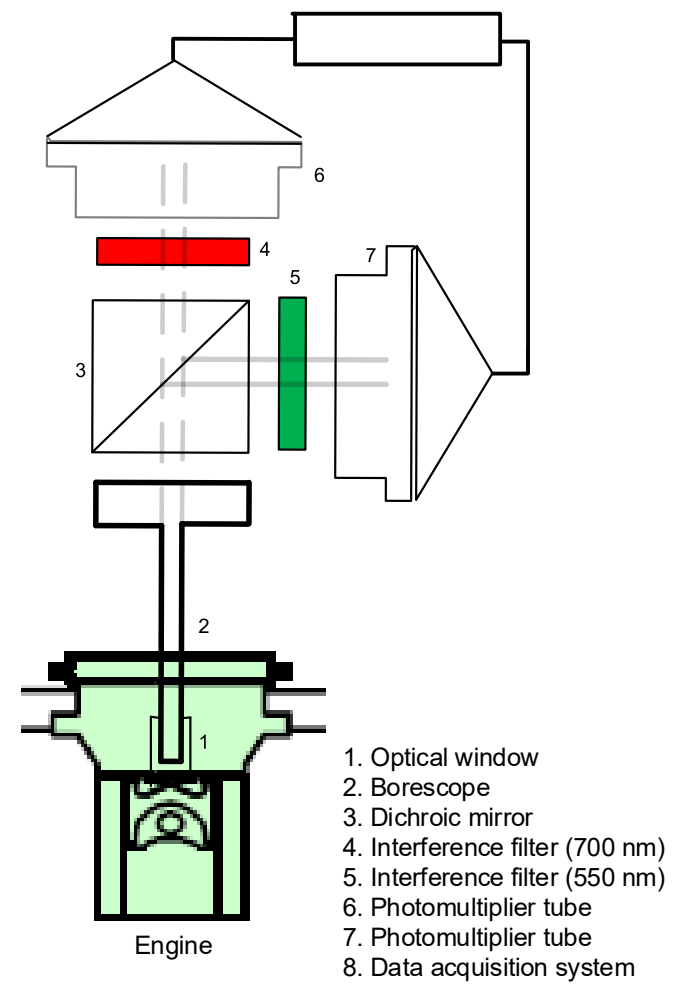

Fig. 2 Schematic of two-colour pyrometry system. For viewing, the camera was mounted directly on the end of the borescope

For calibration, the pyrometer system was configured identically to its in-use arrangement. The borescope was placed horizontally in front of the tungsten strip lamp, targeting the central area of the tungsten lamp, with the tip of the borescope placed within $5 \mathrm{~mm}$ of the tungsten element in the lamp, to minimize spatial variation in radiant intensity across the borescope FOV.

The pyrometer system was calibrated by varying the temperature of the tungsten lamp and recording the measured intensities and the corresponding apparent temperatures. A highly stable direct current (DC) power supply was used to control the temperature, resulting in variations of only $\pm 2 \mathrm{~K}$ in apparent temperature at $660 \mathrm{~nm}$. At each lamp setting, apparent temperatures at $550 \mathrm{~nm}$ and $700 \mathrm{~nm}\left(T_{a l}\right.$ and $T_{a 2}$ ) were measured over a range of PMT gain settings (control voltages of $0.3-0.8 \mathrm{~V})$. the calibration of $T_{a l}(550 \mathrm{~nm})$ is shown in Fig. 3. The pyrometer system was not calibrated below $1300 \mathrm{~K}$ due to increasing fluctuations in the lamp power supply. The correlation between apparent temperatures and output voltages was established as a function of control voltages, with index of correlation $\left(\mathrm{R}^{2}\right)$ greater than 0.998 in all cases. Power relationships are used to fit the trend lines between the PMT voltage and the apparent temperatures. These correlations were used to convert PMT voltage output to apparent temperatures in the subsequent experimental testing.

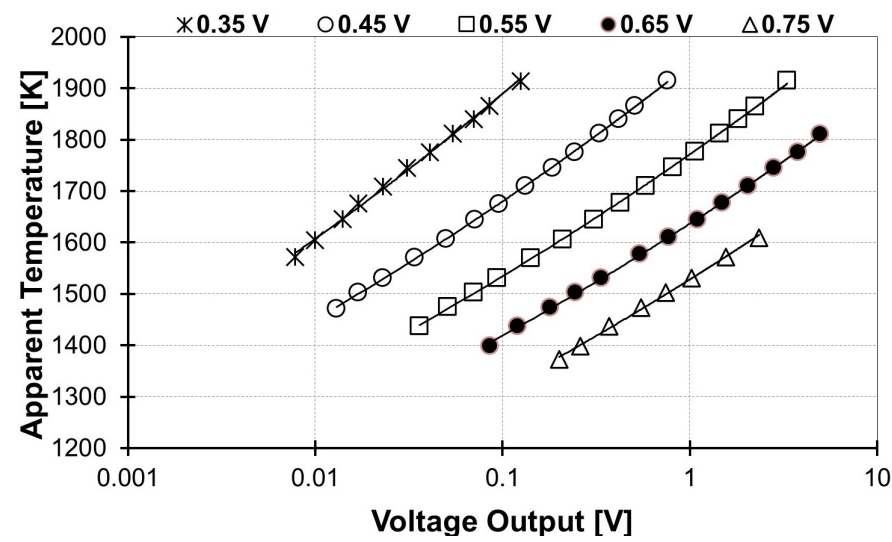

Fig. 3 Calibration of the two-colour pyrometer at $550 \mathrm{~nm}$ wavelength at different PMT control voltages

\section{Sources of Uncertainty}

Various sources of uncertainty in two-colour pyrometry have been identified for conventional diesel combustion. The most relevant include variations in temperature and soot concentration within the resolved region; attenuation of radiation along the optical path; and fouling of the optical window. Due to the low temperatures and low radiant intensity expected from LTC, these sources of uncertainty have the potential to have an even greater impact on the pyrometry results.

Pyrometry results are influenced by attenuation of radiation along the optical path, which is impacted by the particle size distribution and refractive index. Stojkovic et al. [33] reported that typical errors in temperature due to different particle size distribution varied from $2 \%$ to as high as $9 \%$. The lower values are related to smaller primary particles (diameter $<40 \mathrm{~nm}$ ) with low soot concentrations $\left(f_{v} L=0.055\right.$ $\mu \mathrm{m})$ while the higher value corresponds to larger primary particles (up to $60 \mathrm{~nm}$ ) and high soot concentrations $\left(f_{v} L=0.55 \mu \mathrm{m}\right.$ ). In diesel combustion, the width of the mean size distribution of primary soot particles (in-cylinder) are reported to be below $39 \mathrm{~nm}$ (mean particle radii varying between $2 \mathrm{~nm}$ and $23 \mathrm{~nm}$ ) [34] and hence, the error at low soot loadings would be small. Temperature variation through the optical path was found to more significantly impact KL factor, with underestimation of up to $35 \%$ for large temperature differences $(\sim 700$ $\mathrm{K})$. Stojkovic et al., reported that the errors in KL factor would be closer to $2 \%$ for a temperature difference of $150 \mathrm{~K}$ along the line of sight through the soot cloud [33].

Fouling of the optical window may also influence the measured temperature and KL factor [35]. The impact is greater on KL than on temperature, as the $\mathrm{KL}$ factor is proportional to the radiative intensity while the temperature depends on the ratio of radiative intensities at two wavelengths [13]. For the two-colour pyrometry data reported here, the transmissivity of the optical window before and after each set of measurements was not measured. To minimise the effects of window fouling in this work, the optical window was cleaned with iso-propyl alcohol after each experiment. During the testing, no visible window fouling was observed between tests while operating the engine in low-sooting LTC modes.

The largest source of uncertainty for area-integrated two-colour pyrometry is the assumption that temperature and soot loading (KL factor) are homogeneous within the resolved area. Image-based spatially resolved methods overcome this by evaluating multiple 
small regions; the sensitivity and signal to noise ratio are dependent on the camera and the optical techniques used to align the two distinct wavelength measurements [36]. For spatially integrated systems, temperature and KL factor can vary significantly in the resolved region, and in fact significant areas of the field-of-view may not contain any radiating soot. This can tend to skew results towards the high temperature in the reaction zone $[12,19,35,37]$. Yan and Borman [38] reported that the effect of a non-uniform soot loading (KL factor) on the flame temperature measured by the two-colour method is less severe than that of the uneven temperature on the KL factor. This is supported by the work of Payri et al. [19] who modelled the propagation of radiation inside the flame as an emission and absorption process occurring before the measurement device, and showed that for low temperature and/or low KL values, deviations for the two-colour derived KL factor from the nominal KL factor were of the order of $10-20 \%$. On the other hand, for a case of $2100 \mathrm{~K}$ nominal flame temperature and $\mathrm{KL}$ factor $\sim 0.2$, the error between the nominal flame temperature and the two-colour derived flame temperature was found to be $\sim 5 \%$. Areas of the resolved region that do not contain radiating soot may also contribute to a total integrated signal through reflection or radiation from the walls (piston or cylinder liner). While difficult to quantify, the relatively low temperatures of the surfaces and general low reflectivity due to the presence of carbon build-up suggest that these errors should be negligible, at least in the visible wavelengths [35]. Similar to the considerations around soot attenuation, resolved region averaging should impact KL more than $\mathrm{T}$, as KL is dependent on absolute radiative intensity whereas temperature is a function of the ratio of intensities at two distinct wavelengths.

\section{Spatially resolved vs. area integrated measurements}

Spatially resolved flame temperature $(\mathrm{T})$ and $\mathrm{KL}$ factor data from a low-soot combustion process can be used to assess the impacts of spatial variation on area integrated pyrometry results. As the LTC engine facility was not equipped to conduct spatially resolved pyrometry, data from an optically accessible engine with a similarly low-soot combustion was selected for comparison. This engine used a partially premixed, pilot-ignited direct injection of natural gas (PIDING) combustion process and has been extensively reported elsewhere [16,36,39]. The facility uses a Bowditch style extended piston with a quartz insert to image the entire combustion bowl [39]. The pyrometry system uses a single camera with an image doubler that has been carefully calibrated to minimize error [16]. For this study, a randomly selected region of interest (ROI), representing approximately a quarter of the full viewing area, was defined. Sequential frames from the combustion process from a representative low-load operating condition, where the fraction of the ROI which had a measurable radiative intensity increases from $17 \%$ of the total ROI to $100 \%$, were selected for assessment. Spatial T and KL values for a single frame where the sooting area was $\sim 52 \%$ of the total ROI are shown in Figure 4.
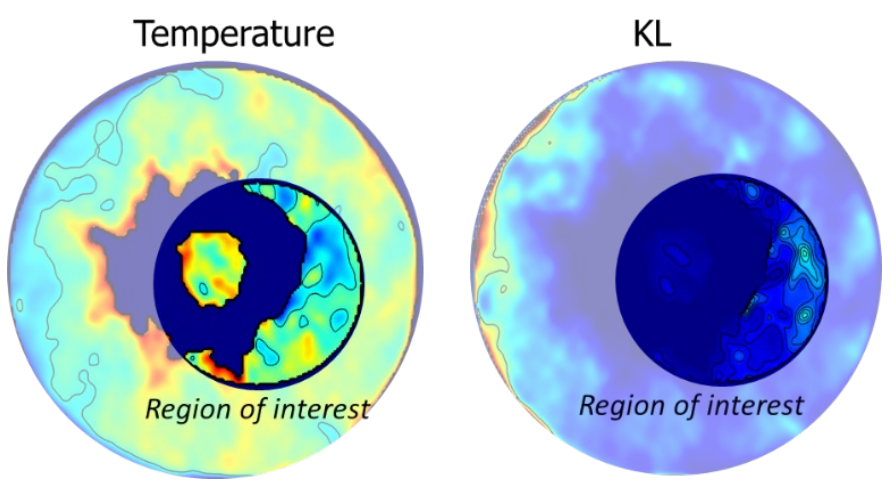

Figure 4: Spatial distribution of T and KL in the full viewing area and in the defined region of interest for partially premixed, pilot-ignited direct injection of natural gas (PIDING) combustion at a low-load, part-premixed strategy. Dark blue are areas with no resolved intensity values. Total resolved sooting (flame) area within the ROI is $\sim 52 \%$.

To assess the integrated values of $\mathrm{T}$ and $\mathrm{KL}$ over the ROI, the recorded intensity data at the two wavelengths (in this case, 700 and $800 \mathrm{~nm}$ ) was averaged over the entire ROI. Three averaging approaches were used: averaging all values; averaging only values with resolved temperature results; and finally, averaging over the entire ROI but replacing zero-containing cells with the minimum intensity recorded within the entire FOV. The spatially integrated (average) temperature and KL factors were then calculated for each approach using Equations 3 and 4. These area integrated values can then be compared with the spatially resolved $\mathrm{T}$ and $\mathrm{KL}$ results from the ROI through data frequency histograms, as shown in Figure 5. As the results show, the first two averaging techniques have only a small impact on the average temperature, which was $2063 \mathrm{~K}$ when all data was included and $2071 \mathrm{~K}$ when considering only non-zero points. Critically, both are centred on the midpoint of the spatially resolved temperature distribution (mean $2089 \mathrm{~K}$; median $2061 \mathrm{~K}$ ). The third approach, where a minimum threshold was applied, overestimates the average temperature by nearly $100 \mathrm{~K}$. KL factors differ substantially for all three averaging approaches; that the underlying KL factor distribution is clearly non-normal indicates that a single spatially integrated result will be less descriptive. Qualitatively, the KL factor when the area integration is corrected for the visible flame in the ROI by removing all cells which were below the detection threshold of the camera (i.e., KL value of 0 ) is representative of the average in the spatially resolved non-zero data (integrated value: 0.083 ; spatially resolved non-zero: median 0.092 , mean 0.11 ). The non-zero data is used as a comparison as these represent the soot concentrations within the combustion chamber. Comparatively, when the zero data points are included, the area integrated KL (0.049) is significantly lower than the spatially resolved data. This demonstrates the importance of incorporating the sooting area in the KL factor calculation. 


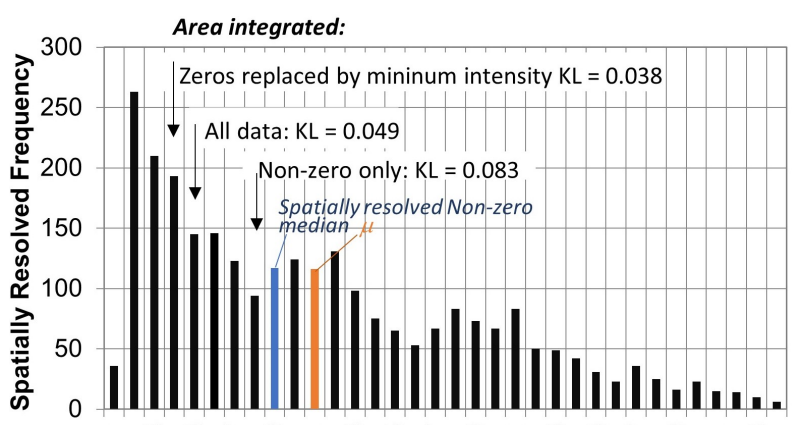

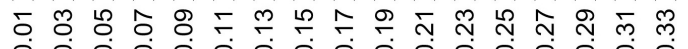

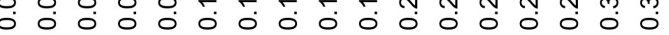
Local Soot Concentration [KL] Area integrated:

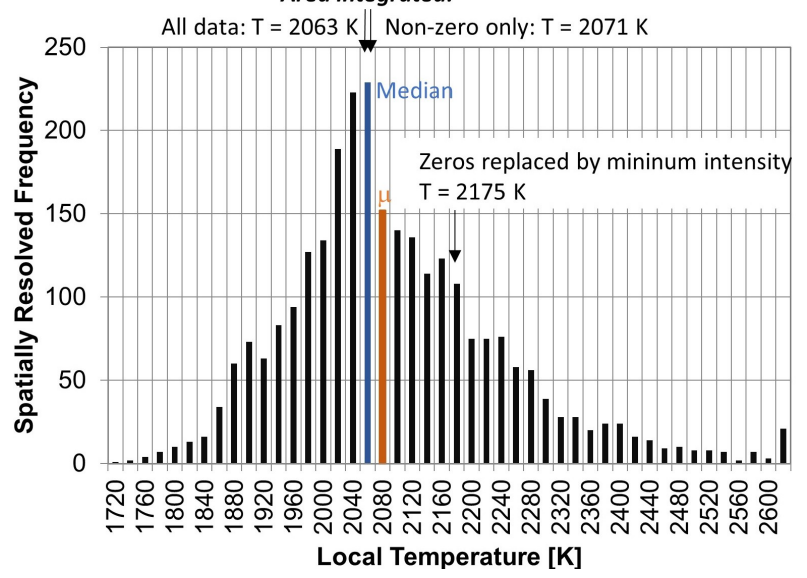

Figure 5: Histograms for spatially resolved T and KL for defined region of interest in PIDING combustion shown in Figure 4. Values shown are the calculated T and KL for area-integrated data, using the average based on: (1) all cells in the ROI (including pixels with 0 values - "All data"); (2) cells containing non-zero data only ("Non-zero only"); and (3) All cells after zero values were replaced by minimum intensity. At this condition, approximately $43 \%$ of the ROI cells contained 0 intensity values.

The results shown in Figure 5 indicate that the average temperature for the integrated ROI is representative of the average spatially resolved temperature in the ROI. However, the KL factors need to be corrected to account for the fact that only part of the ROI is filled with soot emitting a detectable intensity of radiant energy. To account for this sooting area effect, for each of the two wavelengths the apparent temperature in each cell is converted into an incident radiant intensity value using Equation (1). These intensity values are then summed across the entire ROI, providing the total intensity received at the sensor. To correct for the fact that only part of the ROI contains radiating soot, the total intensity is multiplied by the relative sooting area ratio, as in Equation (9). This corrected intensity is then used to calculate a new apparent temperature. When conducted over both wavelengths (700 and $800 \mathrm{~nm}$ for the PIDING engine), a new pair of apparent temperatures are generated. These are then introduced into Equation (4) to solve for a corrected temperature and Equation (3) to determine the corrected KL value.

To assess the applicability of this correction approach, ROIintegrated temperature and KL values have been calculated from the selected sequence of frames with between $17 \%$ and $97 \%$ sooting area in the PIDING engine. This sequence, shown in Figure 6, covers an ignition event where residual heat and radicals from a pilot diesel flame ignites a partially premixed cloud of natural gas (see [36]). The plot shows the $\mathrm{T}$ and KL values calculated from the raw integrated signal (integrated) and after correction for the sooting area. For comparison, the mean and median values from the spatially resolved data are also shown. As expected, the correction has only a small impact on the temperature, which remains between the mean and median of the spatially resolved data. Although the sooting area correction has impacted the absolute values of the apparent temperature, the ratio of apparent temperatures between 700 and 800 $\mathrm{nm}$ has not changed substantially; as a result, the T solution to Equation (4) is not significantly impacted. The KL values, however, show a greater sensitivity to correction; as expected from Equation (3), $\mathrm{KL}$ is dependent on total emissive intensity, so will be sensitive to the sooting area correction. The KL values shown in Figure 6 demonstrate that the uncorrected area-integrated KL is overpredicted compared to the spatially averaged KL (median and mean) when the sooting area is less than $\sim 80 \%$. When the area correction is applied, the integrated KL factor falls between the spatially resolved median and mean values for most of the range of data. Interestingly, at the highest sooting area, both the corrected and uncorrected integrated KL values underpredict the spatial median and mean values by $\sim 10-$ $15 \%$. As the sooting area is nearly $100 \%$ at this point, the correction only has a marginal effect. This may be a result of the highly nonnormal distribution of the KL (shown in Figure 5). While the differences shown in Figure 6 are intriguing, as KL is not considered to be a highly quantitative assessment of soot concentration, these differences are not considered to be significant.
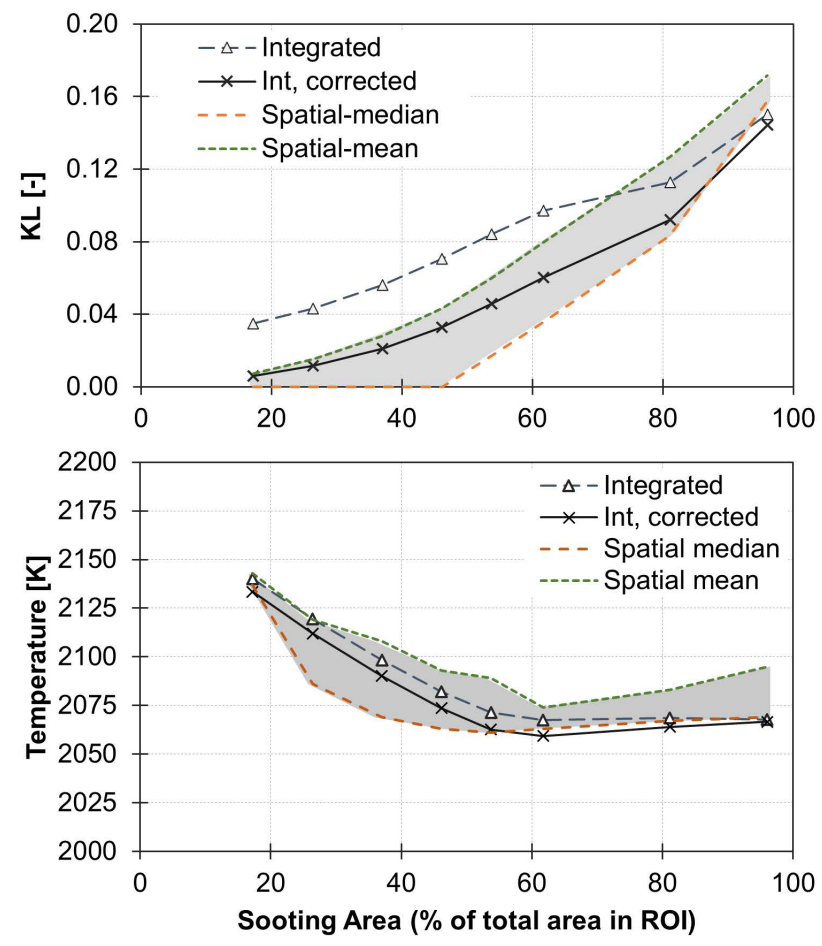

Figure 6: comparison of T and KL calculated from integrating radiant intensity across the ROI compared to the median and mean $\mathrm{T}$ and median $\mathrm{KL}$ values from the spatially resolved PIDING results. Int = integrated; Spatial = spatially resolved. Results corrected for the resolved sooting area (Int, corrected) are also shown for KL.

The results from this comparison between spatially resolved and area-integrated $\mathrm{T}$ and KL values indicates that, for a consistent test condition and with equivalent minimum threshold values for measurement, integrating over a region of interest can provide a representative value for temperature and soot concentration within that area. This forms the basis of the correction approach applied to the borescope based LTC two-colour results that is the main focus of this work. The differences in wavelengths between the PIDING tests $(700$ and $800 \mathrm{~nm})$ and the LTC work (550 and $700 \mathrm{~nm})$ are not expected to impact that applicability of the sooting area correction 
approach. Previous work (e.g. [38], [40]) has shown that for a properly calibrated three-colour pyrometry system, all three wavelength pairs return very similar temperatures and KL factors from conventional diesel combustion. More importantly, in this case, the comparison between the two data sets is not focused on absolute values, but rather on the need to adjust the two-colour pyrometry calculations for the observed sooting area. For the LTC work, spatially resolved data is taken from different cycles and using a different detection system: so, the visible sooting area recorded using the camera may not be fully representative of the total area of radiant emissions detected by the PMTs. Even considering these distinctions, the results from this assessment provide two critical indications: (1) as they are based on a ratio of radiant intensities, calculated temperatures are relatively insensitive to spatial sooting area, and hence no correction needs to be applied; and (2) in conditions with sooting areas $(>\sim 15 \%)$ the sooting area correction can provide a KL value that is generally representative of the average $\mathrm{KL}$ in the entire ROI.

\section{Low Temperature Diesel Operating Conditions}

In order to verify the range and lower limit of the flame temperature measured by the two-colour pyrometer, experiments for both conventional diesel and high-EGR LTC modes were carried out under low-load ( $8 \mathrm{mg} / \mathrm{cycle}$ fuelling quantity, single injection, corresponding to 3 bar IMEP) conditions at a constant engine speed of $1500 \mathrm{rpm}$ in the naturally aspirated (intake pressure $100 \mathrm{kPa}$, absolute) mode. This load ( $25 \%$ of peak load at $1500 \mathrm{rpm})$ is representative of light-load operating conditions where the NOx conversion capability of the aftertreatment system will be reduced. Under these conditions, a near-zero NOx combustion approach is particularly beneficial. Furthermore, the operating condition is also a frequently occurring mode under typical light-duty vehicle operation, such as on the new European Driving Cycle (NEDC) $[6,41]$. The full range of operating conditions examined is specified in Table 3; smoke (PM) and NOx emissions are also provided. Note that the exhaust back pressure was maintained at least $10 \mathrm{kPa}$ above the intake pressure in all the cases to drive the required amount of EGR. With the increase in the EGR rate, the intake oxygen mass fraction decreased from $\sim 23 \%$ (non-EGR) to $12.3 \%$ in the high-EGR LTC strategy (Case C). Intake air temperature was maintained at $45 \pm 5^{\circ} \mathrm{C}$. Engine lubricating oil and coolant temperatures were maintained at $90 \pm 1^{\circ} \mathrm{C}$ and $80 \pm 1^{\circ} \mathrm{C}$, respectively. In-cylinder pressure and radiation signals from the optical pyrometer were acquired at $0.5^{\circ} \mathrm{CA}$ interval; 200 consecutive cycles were recorded and averaged.

Table 3: Test points (Constant engine speed, $1500 \mathrm{rpm})$

\begin{tabular}{|l|l|l|l|l|l|l|}
\hline Case & $\begin{array}{l}\text { Fuel } \\
\text { mass } \\
(\mathrm{mg} /\end{array}$ & $\begin{array}{l}\text { Inj. P. } \\
(\mathrm{MPa})\end{array}$ & $\begin{array}{l}\text { Start of } \\
\text { injection } \\
(\mathrm{SOI}) \\
\text { cycle })\end{array}$ & $\begin{array}{l}\text { Intake } \mathrm{O}_{2} \\
\text { mass } \\
\text { fraction } \\
(\%) /\end{array}$ & $\begin{array}{l}\text { Smoke } \\
(\mathrm{FSN})\end{array}$ & $\begin{array}{l}\text { NOx } \\
(\mathrm{g} / \\
{ }^{\circ} \mathrm{CA} \\
\text { ATDC) }\end{array}$ \\
\end{tabular}

Case A: Conventional Diesel / Low Load; Cases B-C: High-EGR LTC / Low Load

As LTC is expected to produce low, but non-negligible, soot emissions, an AVL415 smoke meter was used to measure exhaust soot, reported in terms of filter smoke number (FSN). Connecting the tailpipe soot to in-cylinder conditions is critical to interpreting both KL and temperature results generated by the pyrometry system for this very temperature sensitive combustion mode.

\section{Results and Discussion}

Region-of-interest integrated pyrometer data is calculated based on the radiant intensities received at the two PMTs, 550 and $700 \mathrm{~nm}$ wavelengths. These values are compared, along with the calculated net energy release rate, in Figures $7 \mathrm{a}$ and $7 \mathrm{~b}$ for the non-EGR conventional diesel combustion (Case A) and high-EGR LTC (Case B), respectively. As would be expected for LTC, the combustion rate is slower and the peak energy release rate is lower than in conventional diesel combustion. This is a direct result of the dilution of the charge and corresponding premixing of the fuel and air prior to ignition [42]. In both cases, the start of the radiation signal coincides with the start of the main energy release rate. This is not surprising, as chemiluminescence from initial reactions during the ignition and cool-flame processes will emit in the ultra-violet region of the spectrum $(<440 \mathrm{~nm})$ and therefore will not be detectable at the wavelengths used in the pyrometer system. 

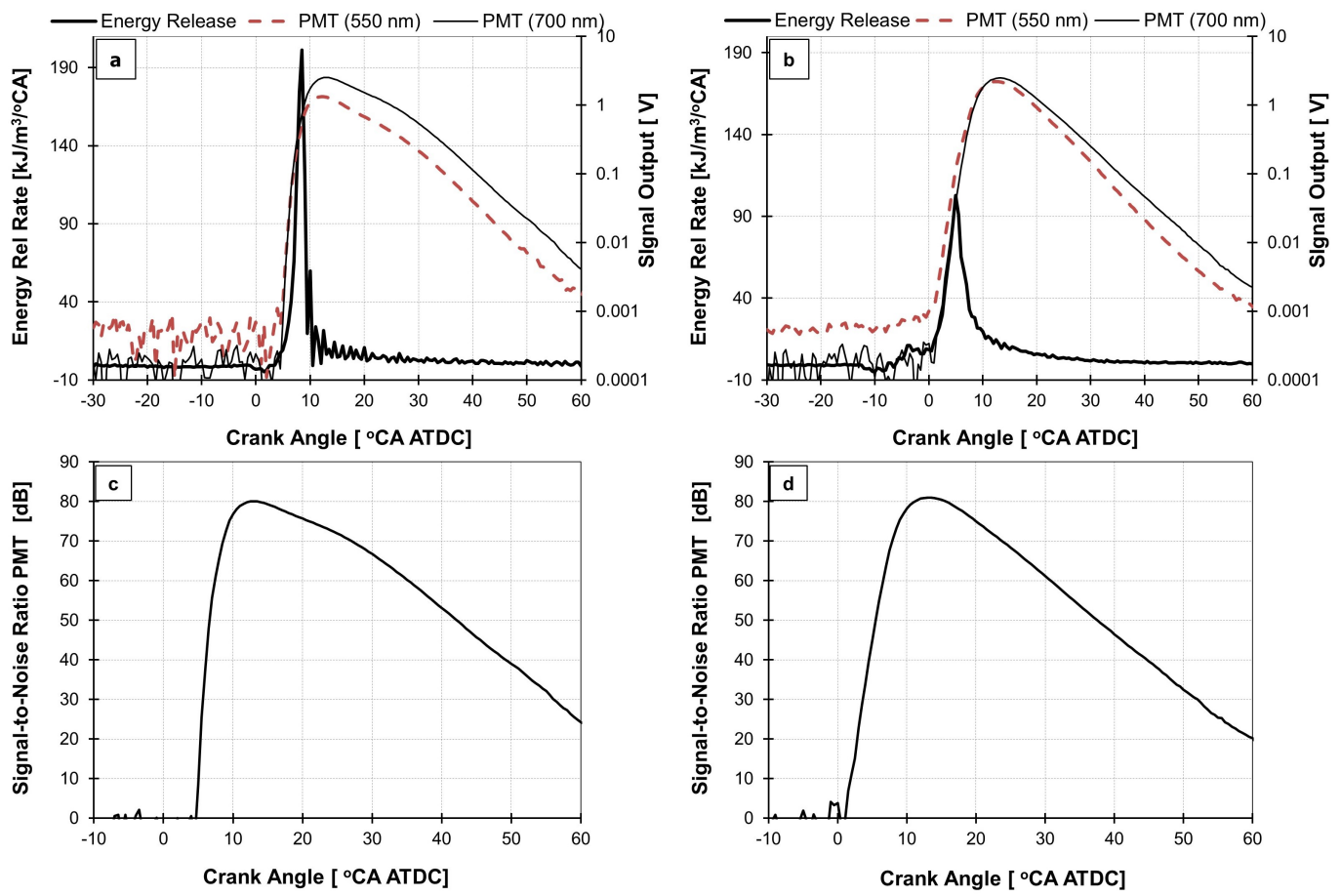

Fig. 7 a. Energy release rate, radiation signals at $550 \mathrm{~nm}$ and $700 \mathrm{~nm}$ of Case A; b. Energy release rate, radiation signals at $550 \mathrm{~nm}$ and $700 \mathrm{~nm}$ of Case B; c. SNR of PMT at $700 \mathrm{~nm}$ in Case A; d. SNR of PMT at $700 \mathrm{~nm}$ in Case B.

The signal to noise ratio (SNR) was determined as a ratio of the measured signal with fuel injection to the noise from an equivalent case without fuel injection; Figs. 7c and 7d show the SNR for conventional diesel and LTC, respectively. In both cases, the SNR was acceptable throughout the main combustion phase, providing confidence in the quality of the data. In general, for this system an $\mathrm{SNR}>65 \mathrm{~dB}$ is considered to be acceptable, although this is recognised as an arbitrary limit.

The average in-cylinder natural luminosity, imaged through the FOV of the borescope (shown in Fig. 1) and averaged over 10 consecutive engine cycles, are shown in Figs. 8a and $8 \mathrm{~b}$ for Cases A and B, respectively. The intensities in these images are not directly comparable. The conventional diesel combustion images (Case A) were recorded with a camera gain of $20 \mathrm{~dB}$ and are presented as recorded (after averaging). The LTC case (Figure 8 b) used a $30 \mathrm{~dB}$ camera gain and to make the region with visible flame more evident in the images, the upper limit of the colour scale was reduced, so that the image was saturated at a pixel intensity of 75 , instead of the 255 used in the raw image. Note that the dark area (sharp curved edges) on the right-hand side of each image is the piston pip as shown in Fig. 1. The FOV of the borescope covers a part of the piston bowl and piston pip. In the conventional diesel case, the visible sooting area filled nearly the entire field of view between 8 and $20^{\circ} \mathrm{CA}$ and decreased rapidly thereafter. In LTC, the luminous area reaches a maximum between 8 and $16{ }^{\circ} \mathrm{CA}$ but never completely fills the field of view; some luminosity remains visible until $28^{\circ} \mathrm{CA}$ ATDC. 


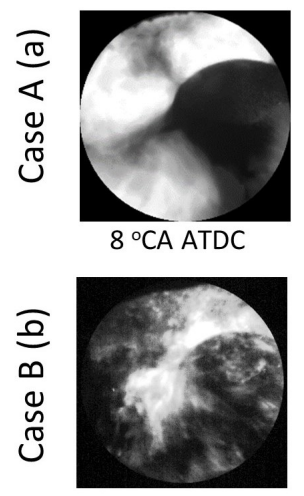

$8^{\circ} \mathrm{CA}$ ATDC

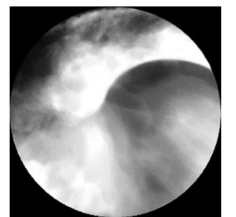

$12^{\circ} \mathrm{CA}$ ATDC

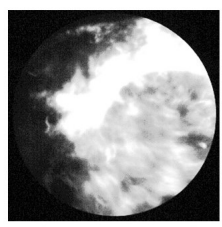

$12{ }^{\circ} \mathrm{CA}$ ATDC

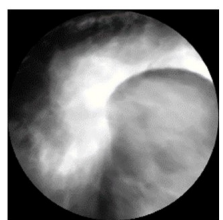

$16{ }^{\circ} \mathrm{CA}$ ATDC

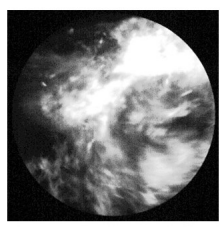

$16{ }^{\circ} \mathrm{CA}$ ATDC

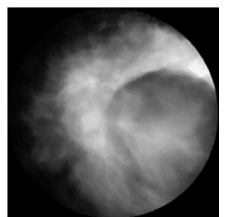

$20^{\circ} \mathrm{CA}$ ATDC

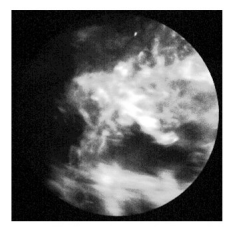

$20^{\circ} \mathrm{CA}$ ATDC
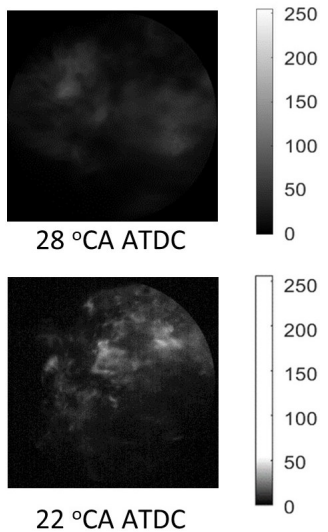

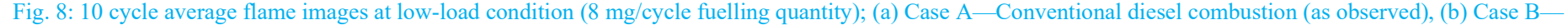

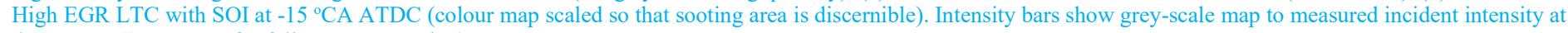
the camera ( 255 counts for full sensor saturation).

Since the FOV of the borescope is not filled up with soot luminosity, it is important to determine the percentage of luminous area so that the KL factor may be corrected to provide meaningful average values within the FOV of the borescope. To assess the sooting (luminous flame) area, the averaged images were processed in Image-Pro Plus 2D image analysis software. For Cases A and B, a threshold intensity of 6 and 4, respectively (out of 255 for the monochrome 8-bit camera) was used; any region above this was identified as having a visible flame. Automated processing was used to define the sooting area boundary, as shown in Figure 9 for both conventional and lowtemperature combustion cases. Note that to avoid introducing

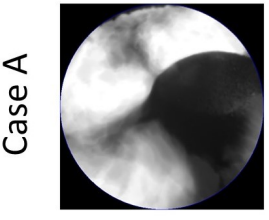

$8^{\circ} \mathrm{CA}$ ATDC

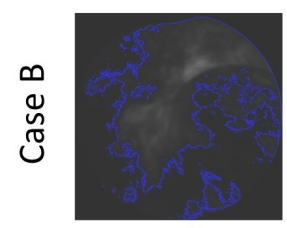

$8^{\circ} \mathrm{CA}$ ATDC

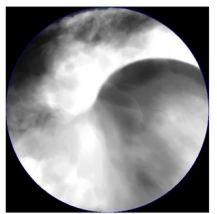

$12{ }^{\circ} \mathrm{CA}$ ATDC

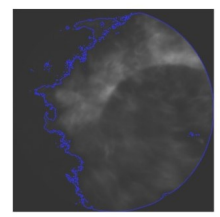

$12^{\circ} \mathrm{CA}$ ATDC

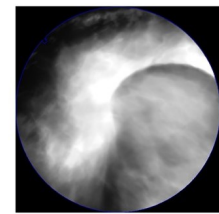

$16^{\circ} \mathrm{CA}$ ATDC

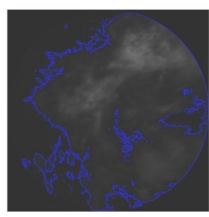

$16^{\circ} \mathrm{CA}$ ATDC

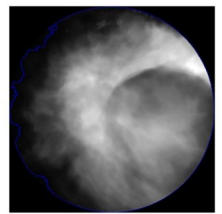

$20^{\circ} \mathrm{CA}$ ATDC

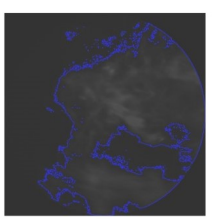

$20^{\circ} \mathrm{CA}$ ATDC

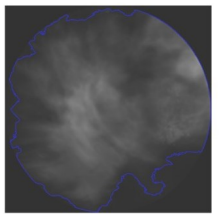

$26^{\circ} \mathrm{CA}$ ATDC

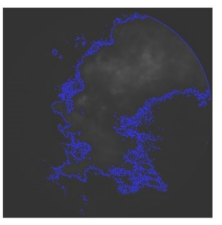

$22^{\circ} \mathrm{CA}$ ATDC

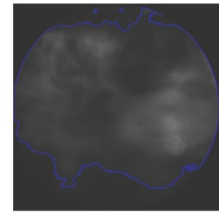

$32^{\circ} \mathrm{CA}$ ATDC

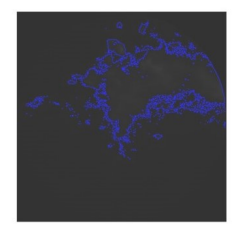

$26^{\circ} \mathrm{CA}$ ATDC

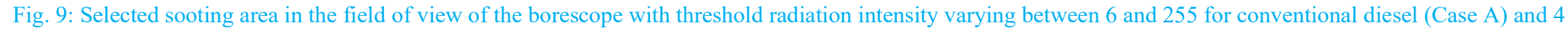
and 255 for LTC (Case B). Grey-scale intensity map is the same as in Figure 8(a) for both cases shown. 


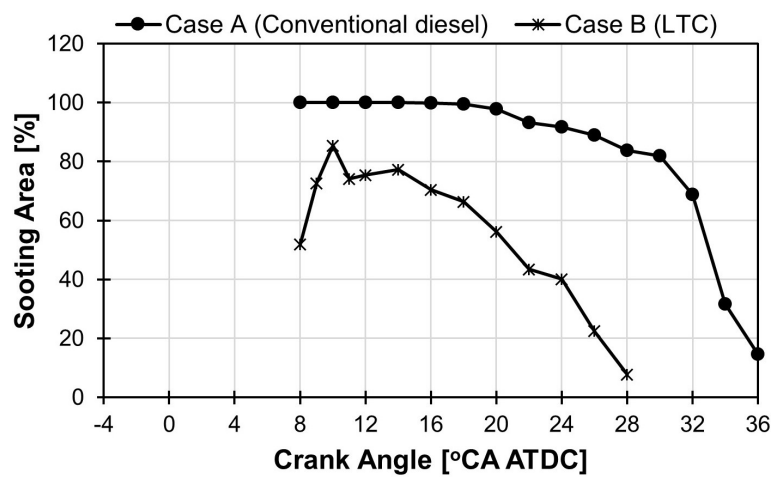

Fig. 10: Soot (flame) area as a fraction of control volume generated by the FOV for conventional diesel and high-EGR LTC cases

The area correction method demonstrated for the spatially resolved PIDING data was implemented by correcting the KL factor for the resolved sooting area. As the sooting (luminous flame) area were determined using a camera with a lower sensitivity than the PMTs used in the pyrometry, it is possible that the actual area from which radiation was emitted was larger than recorded in the camera images. As analysis of the PIDING engine data previously showed, this would not significantly impact the calculated $\mathrm{T}$, but would lead to an overprediction of KL.

With the criteria outlined above, the apparent temperatures, calculated from the PMT voltages and incorporating the calibration factors that incorporate optical system losses, were processed to determine the flame temperature and $\mathrm{KL}$ factor for a baseline conventional diesel and an LTC case (Cases A and B in Table 3), as shown in Fig. 11. Both the uncorrected and corrected flame temperatures and KL factors are shown in the figure. Corrected KL values are only applied for where comparable combustion images containing a non-negligible luminous area are available to define a representative sooting area. For both conventional diesel and LTC cases (Cases A and B), the difference in temperature between the sooting area corrected and the uncorrected (raw) data remained small $(<30 \mathrm{~K})$. The uncertainty in the flame temperatures and KL factors due to random errors (corresponding to a $95 \%$ confidence interval) for Case A (conventional diesel combustion) and Case B (high-EGR LTC) are shown in Figs. 11 (e) and 11(f) respectively. It can be seen from the figures that close to the peak temperature region, the uncertainty in the flame temperature measurements is $\sim 0.2 \%$, whereas it is $\sim 0.5 \%$ in the late combustion phase for conventional diesel combustion and $\sim 0.7 \%$ in the high-EGR LTC condition. The uncertainty in the KL factor for both conventional diesel and highEGR LTC cases is $\sim 10 \%$.

As expected, LTC is characterized by lower peak flame temperature, rapid temperature drop and shorter high-temperature residence time compared to conventional diesel combustion. The corrected KL factor results suggest that soot concentrations are generally significantly lower in-cylinder with LTC compared to conventional diesel, as would be expected. As well, substantial soot luminosity ends earlier in the cycle, suggesting that the remaining energy release may be dominated by oxidation of partially-reacted hydrocarbon species in the low-oxygen, high-equivalence ratio environment of LTC. 

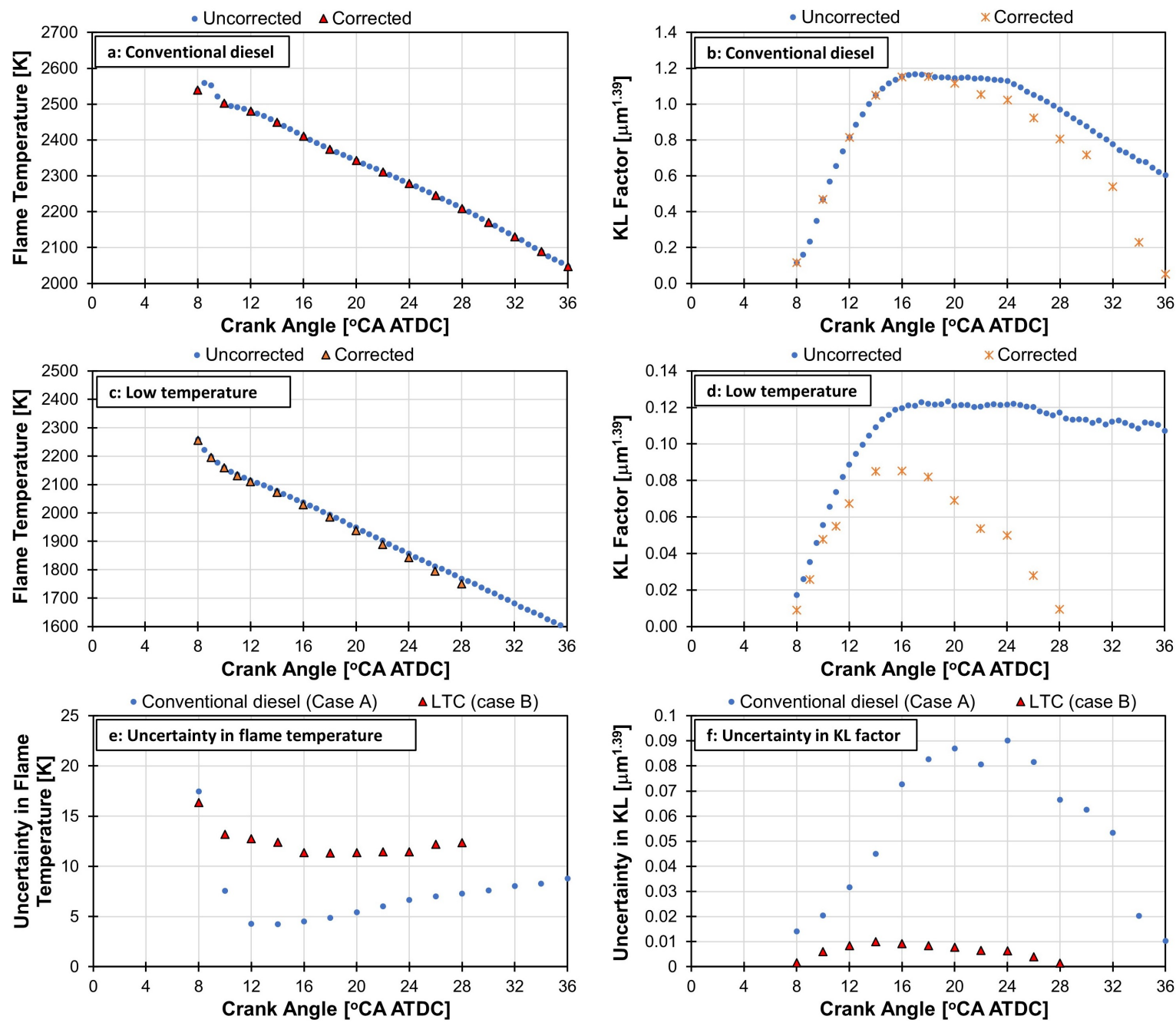

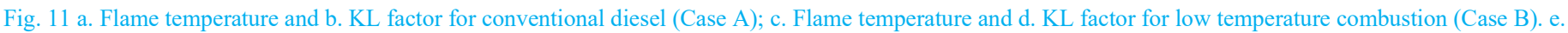

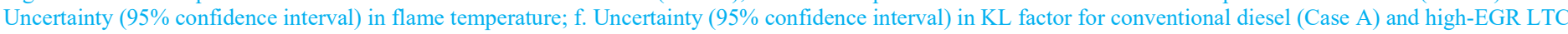
(Case B).

Using the correction methodology developed above, a lowluminosity, high-EGR ( $62 \%$ by volume) LTC case (C in Table 3 ) was assessed using the pyrometer. Sequential images for the peak heat release rate are shown in Figure 12(a), with the image brightness increased in post-processing for image presentation (however, all calculations are based on the original non-intensified images). Only small and indistinct pockets of visible flame are evident. The maximum sooting area as a fraction of the FOV was found to be $\sim 0.5 \%$ (at 6 ${ }^{\circ} \mathrm{CA}$ ATDC), based on an intensity threshold of three (out of 255). Figure 12(a) suggests a larger area of faint (lowluminosity) flame, at such low intensities that much of this area was below the minimum sensitivity threshold. Significant energy release is still observed, and the PMTs do record radiant emissions and the SNR of the PMT is high $(>65 \mathrm{~dB})$ (see Figs. 12 (b) and 12 (c)) even if there is no visible natural luminosity. This suggests that the observed sooting area is likely being significantly underpredicted. The temporal variations of Uncorrected and Corrected flame temperatures and 'Uncorrected', and 'Corrected' KL factors are shown in Figs. 12 (d) and 12 (e) respectively. 


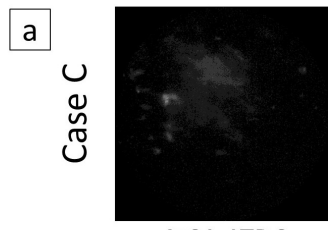

$4^{\circ} \mathrm{CA}$ ATDC

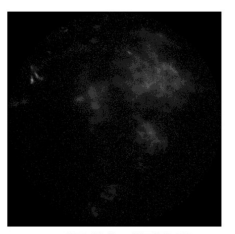

$6^{\circ} \mathrm{CA}$ ATDC

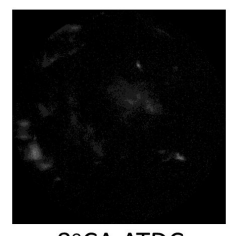

$8^{\circ} \mathrm{CA}$ ATDC

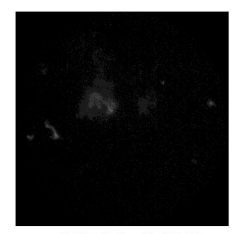

$10^{\circ} \mathrm{CA}$ ATDC

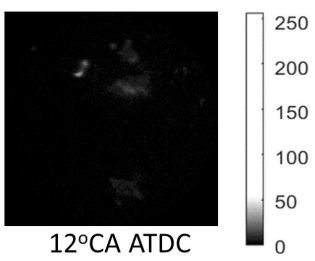

$12^{\circ} \mathrm{CA}$ ATDC
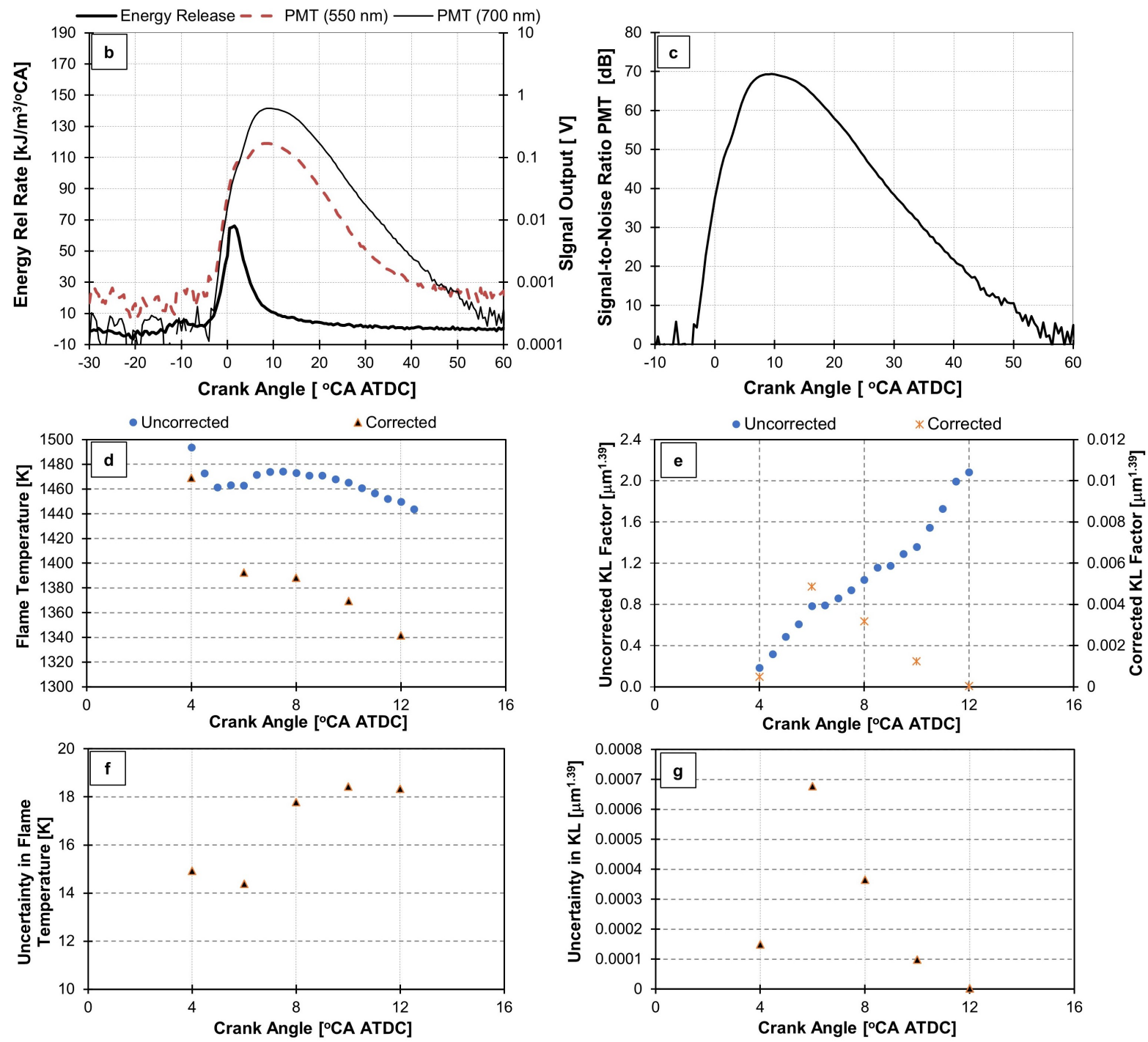

Fig. 12: Flame images at high-EGR advanced SOI $\left(-27^{\circ} \mathrm{CA}\right.$ ATDC) operating condition Case C; (a) flame images, with colour map scaled so that sooting area is discernible, (b) energy release rate, radiation signals at $550 \mathrm{~nm}$ and $700 \mathrm{~nm}$; (c) SNR of PMT at $700 \mathrm{~nm}$ (d) flame temperature (e) KL factor. f. Uncertainty (95\% confidence interval) in flame temperature; g. Uncertainty ( $95 \%$ confidence interval) in KL factor for high-EGR LTC (Case C).

The 'Uncorrected' flame temperature is relatively constant (1494 K to $1450 \mathrm{~K}$ ) over the resolved region (between 4 and $12{ }^{\circ} \mathrm{CA}$ ATDC). However, the 'Corrected' flame temperature reduced significantly from $1470 \mathrm{~K}$ to $1343 \mathrm{~K}$ between the same crank angle interval. Unlike Cases A and B, here the difference between the 'Corrected' and 'Uncorrected' flame temperatures was high and in reality, the actual flame temperature is expected to lie in between these two limits, depending on the actual sooting area. For the PMTs, it is likely that the sooting area was relatively limited at this high-dilution LTC condition; this leads to an unrealistic monotonic increase in $\mathrm{KL}$ at later crank angles for the uncorrected KL, as shown in Fig. 12 (e). This is likely a result of unrepresentative soot luminosity area. Nevertheless, the 'Corrected' KL factors followed the expected trend Page 13 of 16 of the KL factor. Clearly, the PMTs are detecting radiant emissions at intensities below the detection threshold of the camera. Better understanding of the radiating area through, for example an IRtransmitting borescope combined with an intensified camera, could provide a better sooting area definition and correspondingly better estimate - and lower range of uncertainty - for the Case C. Average temperature, however, as being relatively insensitive to sooting area, is likely to still be representative of the average sooting flame temperatures in the borescope FOV. The uncertainties in the flame temperatures and KL factors due to random errors (corresponding to a $95 \%$ confidence interval), shown in Figs. $12 \mathrm{f}$ and $12 \mathrm{~g}$, are $1 \%$ and $10 \%$ respectively. 
These results indicate that there was measurable soot present incylinder during the high-EGR combustion that was not visible by means of natural luminosity imaging. The results then demonstrate the benefits of a PMT based two-colour pyrometry system for lowtemperature and low-soot engine applications - the sensitivity and gain of a typical PMT being substantially greater than those available from either a photodiode or intensified CCD (ICCD) camera system.

\section{Conclusions}

This work investigated the extension of the application of two-colour pyrometry to low temperature and low-sooting advanced diesel engine combustion regimes. A two-colour pyrometry device, with a wavelength pairing of $550 \mathrm{~nm}$ and $700 \mathrm{~nm}$ and signal collection and amplification by means of high sensitivity and high-gain photomultiplier tubes, was developed and calibrated for temperatures down to $1350 \mathrm{~K}$. A borescope with a wide-angle lens was used to provide a broad field-of-view in the combustion chamber. The effect of the visible sooting area within the field of view was assessed based on luminous flame images collected with an imaging system connected to the same borescope. A sooting area correction method was proposed and evaluated based on available data that allows better understanding of spatially integrated pyrometry compared to highspeed imaging and guides interpretation of such integrated measurements. Experiments were performed comparing conventional and low-temperature diesel combustion using the pyrometer in conjunction with field-of-view imaging to provide both flame structure and quantified average temperature and soot concentration at a selected low-load operating condition. The key findings from this work are:

1. Average temperature calculated from a spatially integrated pyrometry system was found to be relatively insensitive to how much of the field of view contained radiant flame. Comparison to spatially resolved results indicated that the calculated pyrometry temperature was between the mean and median of the local temperatures within the field of view.

2. Soot concentration, as quantified by the KL factor, was found to be sensitive to sooting area within the field of view. If the sooting area was not considered, KL factors were found to differ substantially from the spatially resolved values; correcting the KL factor by the observed sooting area brought the pyrometrybased KL factor into closer alignment with the average of the spatially resolved KLs within the field of view.

3. When applied to diluted, low-temperature diesel combustion, the pyrometer resolved temperatures down to $\sim 1350 \mathrm{~K}$, which was the lower calibration limit for the system. Under these conditions, soot emits virtually no discernible light (due to the detection limit of the camera), leading to a visible flame being apparent in less than $1 \%$ of the probe viewing area using a conventional camera. The high gains of the PMTs enabled a reasonable SNR even under this condition, leading to measurements of temperature at highly diluted conditions.

Finally, the authors suggest that the successful implementation of field-of-view integrated two-colour pyrometry provides an opportunity for new insights into low soot producing low temperature combustion diesel engine in-cylinder processes. Further work is needed to refine the sooting area correction method, to enable better assessment of the evolution of soot concentrations under lowtemperature conditions where natural luminosity is weak. As well as further evaluating high-dilution low-temperature combustion, the borescope-based pyrometry technique could also be applicable to other low-soot applications, such as gasoline direct injection or engines fuelled with alternative fuels such as oxygenated alcohols or low-carbon gaseous fuels.

\section{Acknowledgements}

The authors would like to thank Adrian Broster, Steve Horner, Graham Smith and Steve Taylor at Loughborough University's IC Engines and Powertrain Laboratory for their assistance with the optical set up and engine testing. The authors acknowledge Prof. Hua Zhao and Dr Reza Mohammad at Brunel University, London for their support in using their two-colour pyrometer calibration test facility. The suggestions and help of Prof. Graham Hargrave and Dr Graham Wigley of Loughborough University during the development of the two-colour pyrometer are gratefully acknowledged. The PIDING data was collected by Mahdiar Khosravi and Jeremy Rochussen at UBC under NSERC grant CRDPJ 451208-13, and processed by Jake Loftus at SFU. The authors acknowledge financial support from the UK Engineering and Physical Sciences Research Council (EPSRC, Grant F031351/01) and the Royal Academy of Engineering.

\section{Definitions/Abbreviations}

$\begin{array}{ll}\text { ATDC } & \text { After top dead centre } \\ { }^{\circ} \mathrm{CA} & \text { Degree crank angle } \\ \text { CCD } & \text { Charge coupled device } \\ \text { CO } & \text { Carbon monoxide } \\ \text { EGR } & \text { Exhaust gas recirculation } \\ \text { FSN } & \text { Filter smoke number } \\ \text { FOV } & \text { Field of view } \\ \boldsymbol{f}_{v} & \text { Soot volume fraction } \\ I_{\text {soot }} & \text { Soot radiance }\left[\mathrm{W} \cdot \mathrm{m}^{-2} . \mathrm{sr}^{-1}\right] \\ \text { IMEP } & \text { Indicated mean effective pressure }[\mathrm{bar}] \\ \text { IR } & \text { Infra-red } \\ \text { KL } & \text { An indicator of soot concentration }\left[\mu \mathrm{m}^{1.39}\right] \\ \text { L } & \text { Optical path length }[\mu \mathrm{m}] \\ \text { LTC } & \text { Low temperature combustion } \\ \text { NOX } & \text { Nitrogen oxides }\left(\mathrm{NO} \text { and } \mathrm{NO}_{2}\right) \\ \text { PIDING } & \text { Pilot-ignited direct injected natural gas } \\ \text { PM } & \text { Particulate matter } \\ \text { PMT } & \text { Photomultiplier tube } \\ \text { ROI } & \text { Region of interest } \\ \text { SNR } & \text { Signal-to-noise ratio } \\ \text { SOI } & \text { Start of injection } \\ \text { TDC } & \text { Top dead centre } \\ \text { T } & \text { True temperature }[\mathrm{K}] \\ T_{a} & \text { Apparent temperature }[\mathrm{K}] \\ \varepsilon \lambda & \text { Monochromatic emissivity } \\ \lambda & \text { Wavelength [ } \mu \mathrm{m}] \\ & \end{array}$

\section{References}


[1] Dec, E.J., 1997, “A conceptual model of DI diesel combustion based on laser-sheet imaging", SAE Paper No. 970873

[2] Ladommatos, N, Abdelhalim, S and Zhao, H., 2000, "The effects of exhaust gas recirculation on diesel combustion and emissions", International Journal of Engine Research, vol. 1, pp. 107-126. [3] Dec, E.J., 2009, "Advanced compression-ignition enginesunderstanding the in-cylinder processes", Proceedings of the Combustion Institute, vol. 32, no. 2, pp. 2727-2742.

[4] Sarangi, A.K., Garner, C.P., McTaggart-Cowan, G.P., Davy, M.H., and Hargrave, G.K., 2020, "The impact of intake pressure on high exhaust gas recirculation low-temperature compression ignition engine combustion using borescopic imaging", International Journal of Engine Research. doi.org/10.1177/1468087420926024

[5] Sarangi, AK, Garner, CP, McTaggart-Cowan, GP, Davy, MH, Wahab, E, and Peckham, M., 2013, "The effects of split fuel injections on high exhaust gas recirculation low temperature diesel engine combustion", International Journal of Engine Research, vol. 14, pp. 68-79. doi.org/10.1177/1468087412450987

[6] Sarangi, AK, Garner, CP, McTaggart-Cowan, GP, Davy, MH, Wahab, E, and Peckham, M., 2015, "Load transient between conventional diesel operation and low-temperature combustion", Proceedings of IMechE, Part D: Journal of Automobile Engineering, vol. 229 , pp. $850-865$

[7] Matsui, Y., Kamimoto, T., and Matsuoka, S., 1979, “A study on the time and space resolved measurement of flame temperature and soot concentration in a D.I. diesel engine by the two-colour method", SAE Paper No. 790491, SAE Transactions, vol. 88, sec. 2, pp. 18081822

[8] Vattulainen, J., Nummela, V., Hernberg, R., and Kytola, J., 2000, "A system for quantitative imaging diagnostics and its application to pyrometric in-cylinder flame-temperature measurements in large diesel engines", Measurement Science and Technology, vol. 11, no. 2, pp. 103-119

[9] Benajes, J., Martin, J., Garcia, A., Villalta, D., and Warey, A., 2015, "In-cylinder soot radiation heat transfer in direct injection diesel engines", Energy Conversion and Management, vol. 106, pp. 414-427

[10] Kamimoto, T., Uchida, N., Aizawa, T., Kondo, K., and

Kuboyama, T., 2017, "Diesel flame imaging and quantitative analysis of in-cylinder soot oxidation", International Journal of Engine Research, vol. 18, pp. 422-435

[11] Singh, S., Reitz, R.D., and Musculus, M.P.B., 2005, "2-color thermometry experiments and high-speed imaging of multi-mode diesel engine combustion", SAE Paper No. 2005-01-3842

[12] Musculus, M.P.B., Singh, S., and Reitz, R.D., 2008, "Gradient effects on two-color soot optical pyrometry in a heavy-duty DI diesel engine", Combustion and Flame, vol. 153, pp. 216-227

[13] Diez, A., Zhao, H., Carrozzo, T., Catania, A.E., and Spessa, E., 2011, "Development of a high-speed two-colour system and its application to in-cylinder diesel combustion temperature and soot measurements with split injections", Proceedings of IMechE, part D: Journal of Automobile Engineering, vol. 226, pp. 684-697 [14] Zhang, J., Jing, W., Roberts, W.L., and Fang, T., 2014, "Soot measurements for diesel and biodiesel spray combustion under high temperature highly diluted ambient conditions", Fuel, vol. 135, pp. 340-351

[15] Colban, W.F., Kim, D., Miles, P.C., Oh, S., Krieger, R., Foster, D., Durrett, R.P., and Gonzalez, A., 2009, "Detailed comparison of emissions and combustion performance between optical and metal single-cylinder diesel engines at low temperature combustion conditions", SAE International Journal of Fuels and Lubricants, vol. 1, pp. 505-519

[16] Khosravi, M. and Kirchen, P. 2019. "Refinement of the twocolor pyrometry method for application in a Direct Injection Diesel and Natural Gas Compression-Ignition Engine". Proceedings of the Institution of Mechanical Engineers, Part D: Journal of Automobile Engineering. 233(4). 3787-3800.

Page 15 of 16 https://doi.org/10.1177/0954407019832774

[17] Zhao, H., and Ladommatos, N., 1998, "Optical diagnostics for soot and temperature measurement in diesel engines", Progress in Energy and Combustion Science, vol. 24, no. 3, pp. 221-255

[18] Musculus, M.P.B., 2005, "Measurement of the influence of soot radiation on in-cylinder temperatures and exhaust NOx in a heavyduty DI diesel engine", SAE Journal of Engines, vol. 114, pp. 845866

[19] Payri, F., Pastor, J.V., Garcia, J.M., and Pastor, J.M., 2007, "Contribution to the application of two-colour imaging to diesel combustion", Measurement Science and Technology, vol. 18, pp. 2579-2598

[20] Hessel, R., Yue, Z., Reitz, R., Musculus, M., and O’Connor, J., 2017, "Guidelines for interpreting soot luminosity imaging", SAE International Journal of Engines, vol. 10, pp. 1174-1192

[21] Hottel, H.C., and Broughton, F.P., 1932, "Determination of true temperature and total radiation from luminous gas flames", Industrial and Engineering Chemistry Analytical Edition, vol. 4, no. 2, pp. 166175

[22] Sarangi, A.K., 2012, "Diesel Low Temperature Combustion An Experimental Study", PhD Thesis, Loughborough University, Loughborough, UK

[23] Heywood, J.B., 2018, "Internal Combustion Engines

Fundamentals" $2^{\text {nd }}$ Edition, McGraw Hill Book Company, USA

[24] Cong, S., Garner, C.P., and McTaggart-Cowan, G.P., 2010, “The effects of exhaust back pressure on conventional and low-temperature diesel combustion", Proceedings of the IMechE, Part D: Journal of Automobile Engineering, vol. 225, pp. 222-235

[25] AVL List GmbH, 2009, "Instruction manual for cylinder head with endoscopic access for AVL 5402 single cylinder research engine no. 5402.055",

[26] Stasio, S., and Massoli, P., 1994, "Influence of the soot property uncertainties in temperature and volume-fraction measurements by two-colour pyrometry", Measurement Science and Technology, vol. 5, pp. $1453-1465$

[27] Gaydon, A.G., 1974, “The Spectroscopy of Flames”, Chapman and Hall Ltd, London

[28] Seinfeld, J.H., and Pandis, S.N., 1998, “Atmospheric Chemistry and Physics: From Air Pollution to Climate Change". John Wiley \& Sons, New York

[29] Jones, T.P., 1963, "The suitability of tungsten strip lamps as secondary standard sources in photoelectric pyrometry", J. Sci.

Instrum., vol. 40, pp. 101-104

[30] Herfatmanesh, M.R., 2010, "Investigation of single and split injection strategies in an optical diesel engine", $\mathrm{PhD}$ Thesis, Brunel University, West London, UK

[31] Larrabee, R.D., 1959, "Spectral emissivity of tungsten", Journal of the Optical Society of America, vol. 49, no. 6, pp. 619-625 [32] Lu, G., and Yan, Y., 2006, "Temperature profiling of pulverized coal flames using multicolour pyrometric and digital imaging techniques", IEEE Transactions on Instrumentation and Measurement, vol. 55, no. 4, pp. 1303-1308

[33] Stojcovic, B.D., Fansler, T.D., Drake, M.C., and Sick, V., 2005, "High-speed imaging of $\mathrm{OH}^{*}$ and soot temperature and concentration in a stratified-charge direct-injection gasoline engine", Proceedings of the Combustion Institute, vol. 30, pp. 2657-2665

[34] Ryser, R., Gerber, T., and Dreier, T., 2009, "Soot particle sizing during high-pressure Diesel spray combustion via time-resolved laser-induced incandescence", Combustion and Flame, vol. 156, pp. $120-129$

[35] Matsui, Y., Kamimoto, T., and Matsuoka, S., 1980, "A study on the application of the two-colour method to the measurement of flame temperature and soot concentration in diesel engines", SAE Paper No. 800970, SAE Transactions, vol. 89, sec. 3, pp. 3043-3055 [36] Khosravi, M., McTaggart-Cowan, G., and Kirchen, P, 2020, "Pyrometric imaging of soot processes in a pilot ignited direct 
injected natural gas engine". International Journal of Engine

Research. Online-first, June 2020.

doi.org/10.1177/1468087420919196

[37] Svensson, K.I., Mackrory, A.J., Richards, M.J., and Tree, D.R., 2005, "Calibration of an RGB, CCD camera and interpretation of its two-colour images for KL and temperature", SAE Paper No. 200501-0648

[38] Yan, J., and Borman, G.L., 1988, “Analysis and in-cylinder measurement of particulate radiant emissions and temperature in a direct injection diesel engine", SAE Paper No. 881315

[39] Rochussen, J., McTaggart-Cowan, G., Kirchen, P. 2020.

"Parametric study of pilot-ignited direct-injection of natural gas combustion in an optically accessible heavy-duty engine" International Journal of Engine Research. 21(3). 497-513. doi.org/10.1177/1468087419836877

[40] Kirchen, P., Obrecht, P., Boulouchos, K., and Bertoal, A., 2010, "Exhaust-stream and in-cylinder measurements and analysis of the soot emissions from a common rail diesel engine using two fuels",
Journal of Engineering for Gas Turbines and Power, vol. 132, pp. 112804-1-112804-8. doi.org/10.1115/1.4001083

[41] Sarangi, A.K., Garner, C.P., McTaggart-Cowan, G.P., Davy, M.H., Wahab, E.A., and Peckham, M.S., 2012, "Managing the transition between low temperature combustion and conventional diesel combustion during a load change", ASME Internal Combustion Engine Division Fall Technical Conference, vol. 55096, pp. 243-255.

[42] Cong, S., McTaggart-Cowan, G.P., Garner, C.P., Wahab, E., and Peckham, M. 2011. "Experimental investigation of low temperature diesel combustion processes" Comb Sci. Tech., vol. 183, pp. 13761400. doi.org/10.1080/00102202.2011.600740 